\title{
Microsecond Electroporator Optimization for Parasitic Load Handling and Damping
}

\author{
Vitalij Novickij ${ }^{1,2}$, Voitech Stankevic ${ }^{1}$, Audrius Grainys ${ }^{1,2}$, Jurij Novickij ${ }^{1,2}$, Sonata Tolvaisiene ${ }^{1}$ \\ ${ }^{I}$ Department of Electrical Engineering, Vilnius Gediminas Technical University, \\ Naugarduko 41, LT-03227 Vilnius, Lithuania \\ ${ }^{2}$ High Magnetic Field Institute, Vilnius Gediminas Technical University, \\ Naugarduko 41, LT-03227 Vilnius, Lithuania \\ vitalij.novickij@vgtu.lt
}

\begin{abstract}
During development of the pulsed power generators the occurrence of the parasitic elements in the circuit is inevitable, which leads to appearance of overvoltage, overcurrent and waveform distortions. This work is focused on the optimization of the microsecond electroporator to enable handling and damping of the parasitic loads. The optimization is based on a flexible PSPICE model of the electroporator, which is used for the compensation of the parasitic parameters. Based on the modelling results the parameters and the circuit elements for the device are selected. The compliance of the prototype's experimental and the PSPICE simulated output pulses is analysed. The optimized circuit of the microsecond electroporator is designed. The system supports current handling up to $100 \mathrm{~A}$ and capable to generate up to $4 \mathrm{kV}$ square wave pulses.
\end{abstract}

Index Terms-Electroporation, pulsed power, stray inductance, compensation.

\section{INTRODUCTION}

Electroporation is a biomedical technique, which is applied for the targeted and controlled delivery of drugs and other molecules into the cells by means of increase of the cell membrane permeability [1]-[3].

The high voltage generators are required for the high intensity electric field generation, which induces reversible and non-reversible cell permeability increase effects [4]-[6]. As a rule a controlled discharge of a capacitor array through the biological load using a pulse forming switch is applied [7]. However, when the load is increased and the commutated voltage is in the range of several kilovolts, the influence of the stray inductance and other parasitic circuit components is inevitable [8]. Appearance of transient overvoltage and overcurrent can damage the switch, distort the output waveform and introduce safety issues during operation of the device. The design and implementation of the compensation circuits for parasitic load handling and damping is required [9]-[10].

Compensation of the parasitic elements involves limitation of the circuits' $d I / d t$ and $d V / d t$ [11]-[12]. Damping of the reverse biased voltage and current is also required. However, implementation of the compensation circuit without preliminary analysis of the transient processes could result in an over-damped or under-damped response, which is in both cases undesirable and may result in irreversible damage of the electroporator or poor pulse generation flexibility.

In this work we present a flexible microsecond electroporator optimization using PSPICE model of the device, which can be used to estimate the influence of transient processes during pulse generation and allows design and implementation of the compensation circuit for parasitic load handling and damping. Optimization of the $4 \mathrm{kV}, 100$ A electroporator based on IXEL40N400 IGBT switch is performed. The adequacy of the proposed model is evaluated experimentally.

\section{DeVelopment of The Compensation CiRCUIT}

As it has been mentioned above the conventional way of generation of the square-wave electrical pulse is the discharge of the capacitor array through the load using a controlled opening time switch. In this study an insulated gate bipolar transistor (IGBT) switch is applied. The IGBT is the best choice in the micro-millisecond diapason due to the relatively fast rise and fall times and the high power handling capability compared to the metal-oxidesemiconductor field-effect transistor (MOSFET).

In order to determine the influence of the parasitic components and develop a compensation circuit for the microsecond electroporator a PSPICE model has been introduced. The PSPICE modeled circuit is shown in Fig. 1.

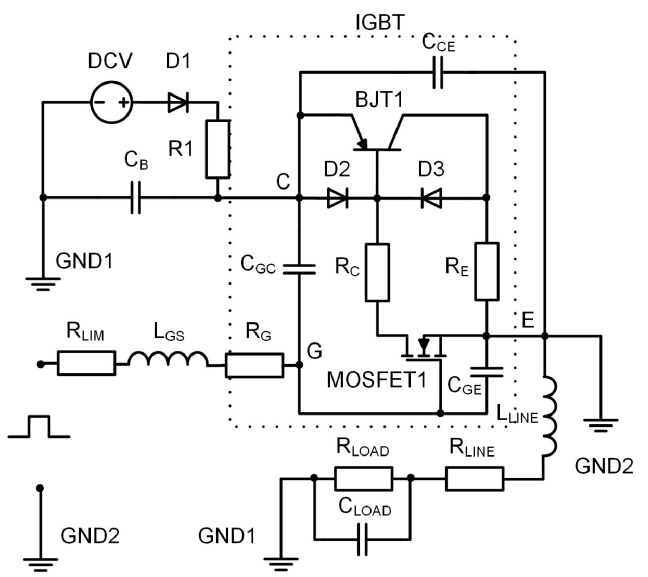

Fig. 1. PSPICE model of the electroporator based on IGBT switch 
The model consists of the voltage source that charges the main capacitor bank $\mathrm{C}_{\mathrm{B}}$, IGBT model, the load and the parasitic components that are expected in the circuit. Essentially, the IGBT switch is a MOSFET with additional layer in series with the collector, which implies that it could be simulated as a power MOSFET1 and a bipolar PNP transistor BJT1. The voltage breakdown features of the simulated switch are introduced using diodes D2 and D3. The stray capacitances, and the IGBT inner resistances are also simulated as $\mathrm{C}_{\mathrm{GC}}, \mathrm{C}_{\mathrm{GE}}, \mathrm{C}_{\mathrm{CE}}$ and the $\mathrm{R}_{\mathrm{C}}, \mathrm{R}_{\mathrm{E}}, \mathrm{R}_{\mathrm{G}}$, respectively. The parameters of the IGBT have been altered to match the datasheet switching characteristics of the IXEL40N400 IGBT switch by Ixys (USA).

The IGBT is driven by an external signal, while the resistor $\mathrm{R}_{\mathrm{LIM}}$ limits the driving signal power. The $\mathrm{L}_{\mathrm{GS}}$ is the stray inductance of the driver circuit. The load of the electroporator is a cuvette with cell suspension. The load has been simulated as a resistor $R_{\text {LOAD. The parasitic }}$ components of the load such as contact capacitance, resistance of the transmission line and the stray inductance have been introduced as $\mathrm{C}_{\mathrm{LOAD}}, \mathrm{R}_{\mathrm{LINE}}, \mathrm{L}_{\mathrm{LINE}}$, respectively. The summary of adjustable model parameters is presented in Table I.

\section{TABLE I. PSPICE MODEL PARAMETERS.}

\begin{tabular}{|c|c|c|}
\hline Parameter & Value range & Denotation \\
\hline Power supply capacitance & $1 \mu \mathrm{F}-1 \mathrm{mF}$ & $\mathrm{C}_{\mathrm{B}}$ \\
\hline Power supply limiting resistance & $20 \mathrm{k}-80 \mathrm{k}$ & $\mathrm{R} 1$ \\
\hline Collector-emitter capacitance & $200 \mathrm{pF}-300 \mathrm{pF}$ & $\mathrm{C}_{\mathrm{CE}}$ \\
\hline Gate-collector capacitance & $50 \mathrm{pF}-200 \mathrm{pF}$ & $\mathrm{C}_{\mathrm{GC}}$ \\
\hline Gate-emitter capacitance & $1 \mathrm{nF}-10 \mathrm{nF}$ & $\mathrm{C}_{\mathrm{GE}}$ \\
\hline Inner gate resistance & $1-10$ & $\mathrm{R}_{\mathrm{G}}$ \\
\hline $\begin{array}{c}\text { Driving signal power limiting } \\
\text { resistance }\end{array}$ & $1-40$ & $\mathrm{R}_{\mathrm{GS}}$ \\
\hline Driver circuit stray inductance & $0.5 \mu \mathrm{H}-2 \mu \mathrm{H}$ & L $_{\mathrm{GS}}$ \\
\hline Transmission line stray inductance & $2 \mu \mathrm{H}-10 \mu \mathrm{H}$ & $\mathrm{L}_{\mathrm{LINE}}$ \\
\hline Load resistance & $40-2 \mathrm{k}$ & $\mathrm{R}_{\mathrm{LOAD}}$ \\
\hline Parasitic load capacitance & $1 \mathrm{pF}-800 \mathrm{pF}$ & $\mathrm{C}_{\mathrm{CAP}}$ \\
\hline
\end{tabular}

The pulse forming capabilities of the simulation circuit have been evaluated. In order to determine the required compensation for the transient processes during switching the influence of the parasitic circuit parameters $L_{\text {LINE }}$ and $\mathrm{C}_{\mathrm{LOAD}}$ have been analysed. The dependence of the generated 2 s pulse waveform on the stray inductance $\mathrm{L}_{\text {LINE }}$ is shown in Fig. 2.

As it can be seen in Fig. 2 due to parasitic inductance in the circuit the aberration from the square waveform is observed. The maximum allowed load of 40 has been used in the model to estimate the maximum loop effect, which may appear in the circuit, during high current flow. The rise time of the pulse is increased dramatically to $0.5 \mathrm{~s}-0.7 \mathrm{~s}$ dependent on the stray inductance value. The switching delay of $200 \mathrm{~ns}-500 \mathrm{~ns}$ that is introduced in the simulation is typical for IGBTs, therefore was also implemented in the model to improve the adequacy of results. The voltage spikes and oscillations during turn-off of the IGBT are proportional to the total loop inductance of the electroporators' transmission line, which in the real prototype comes from PCB tracks, terminal leads, inner electronic component inductance and wire-bond connections.

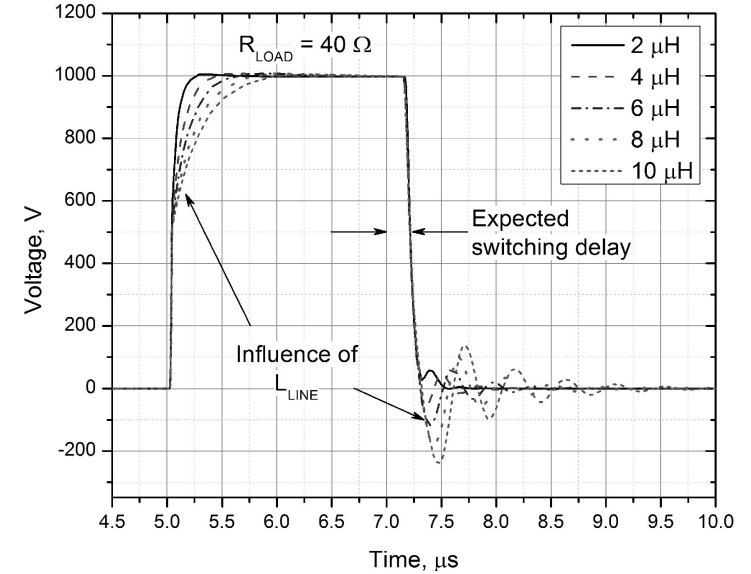

Fig. 2. The influence of the stray inductance on the generated pulse waveform.

Combined with the self-inductance in high power electronic components the minimum total expected value of inductance is in the $2 \mathrm{H}-7 \quad \mathrm{H}$ range. The wire connections contribute as much as $<10 \%$ of the total expected circuit inductance, however minimizing this value is still advantageous.

Another non-desired parameter influencing the output pulse shape is the parasitic capacitance. This parameter mainly impacts the rise time of the pulse during turn on of the high voltage IGBT. During turn-on there is a risk of high inrush current forming due to the charging of the stray capacitance, however it can be diminished by a ballast resistor in series with the load. In order to estimate the effect of the stray capacitance on the output pulse of the generator without compensation circuit the $\mathrm{C}_{\mathrm{LOAD}}$ parameter influence has been investigated in the model and is presented in Fig. 3.

A voltage spike below $10 \%$ of the total pulse amplitude could be acquired when the $800 \mathrm{pF}$ stray capacitance is present in the circuit. However, if the total stray inductance of the circuit will be higher than $2 \mathrm{H}$ or a series to the load ballast resistor is implemented, the effect of stray capacitance according to the proposed model is not significant and could be neglected.

The IGBTs have a significantly lower on state voltage compared to the MOSFETs, the high current and power handling capability and the high breakdown voltage limit makes it a better fit for the proposed application.

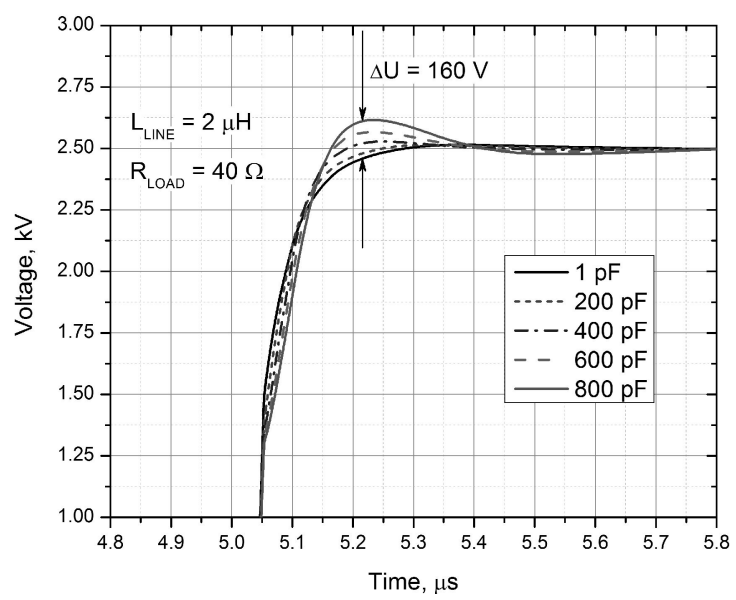

Fig. 3. The influence of the stray capacitance on the generated pulse waveform. 
However, one of disadvantages of the IGBT that will influence the output pulse of the generator is the tail current during turn off, until the charge carriers are swept out and recombined in the semiconductor structure of the switch. The influence of the tail current could be minimized by increase of the gate current, however the risk of the IGBT latchup increases. If the driving signal power is outside of the datasheet rating, the IGBT can fail and no longer be controlled by the transistor's gate. According to the datasheet, the optimal $\mathrm{R}_{\mathrm{GS}}$ for the IGBT is in the range of 30 . The current tail of the IGBT has been evaluated using the model at maximum load and in the $0 \mathrm{kV}-4 \mathrm{kV}$ voltage range. The results of the simulation are presented in Fig. 4.

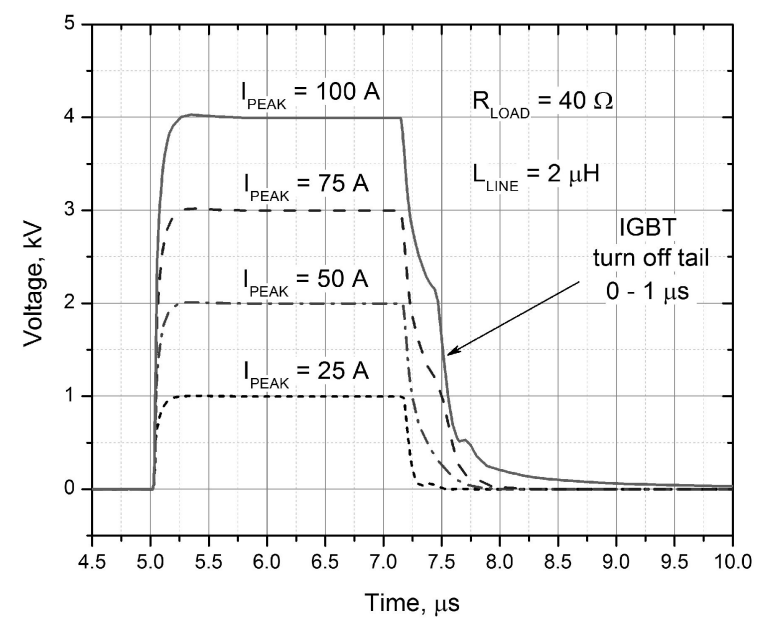

Fig. 4. The influence of the IGBT current tail on the pulse waveform.

As it can be seen in Fig. 4 up to $0.5 \mathrm{~s}-1 \mathrm{~s}$ increase of the fall time could be observed due to the tail current of the IGBT. Decrease of the gate resistance below the recommended value may involve safety issues due to the possible IGBT failure, therefore the minimum value of 30 has been selected.

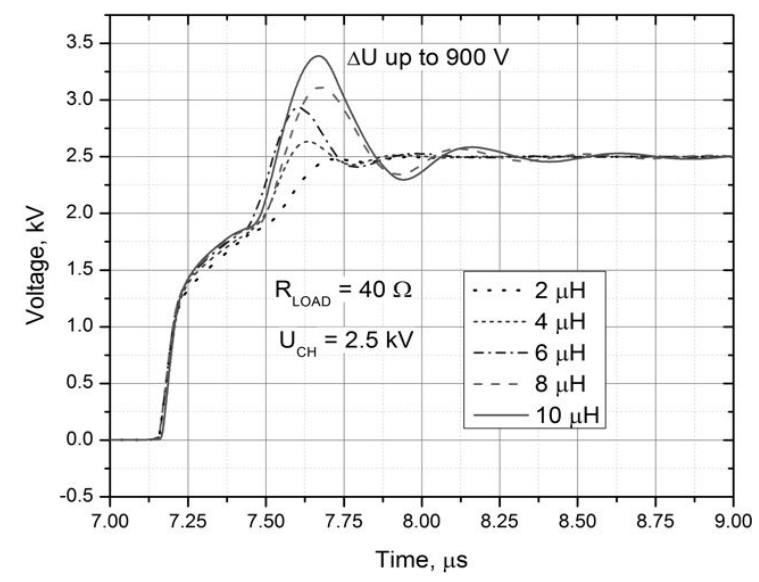

Fig. 5. Transient processes on the IGBT switch during turn-off.

One of the most important tasks during development of the electroporator is to protect the pulse forming switch from overvoltage and overcurrent. The oscillations occur due to the reverse biased current generated in the circuit by the parasitic inductive loop. Especially, the voltage spikes are experienced on the IGBT switch during transient state of turn-off. In order to prevent overvoltage issues on the IGBT, the switch transient processes dependence on the stray inductance of the circuit was investigated. The voltage spikes on the switch have been simulated with a 40 load with various stray inductance in the circuit and are shown in Fig. 5.

As it can be seen in Fig. 5 the overvoltage protection circuit will be required in the prototype. The reverse biased voltage can reach up to $36 \%$ of the total pulse amplitude if the stray inductance is in the $10 \mathrm{H}$ range. In the proposed application of the IXEL40N400, there is no reserve in the collector-emitter voltage, which implies that the generated voltage during transient processes is outside the applicable ratings of the switch if a $4 \mathrm{kV}$ pulse is formed. Also reversebiased voltage will discharge the capacitor bank $C_{B}$ more rapidly, which is not desirable for repetitive pulsing.

In order to compensate the transient processes and improve the generated pulse shape an overvoltage protection circuit was developed, which includes RCD snubber and crowbar diode topology $\left(\mathrm{D}_{\mathrm{C} 1}\right.$ and $\left.\mathrm{D}_{\mathrm{C} 2}\right)$. The circuit is shown in Fig. 6. The crowbar diodes damp the induced current through the load. The snubber diodes $\mathrm{D}_{\mathrm{S} 1}$ and $\mathrm{D}_{\mathrm{S} 2}$ prevent reverse biased current flow to discharge the capacitor bank $C_{B}$. Also the $D_{S 2}$ prevents the reverse biased voltage spikes on the switch. RC snubber is implemented to limit the $\mathrm{dI} / \mathrm{dt}$ in the circuit and have a reserve in time for the recovery of the snubber diodes.

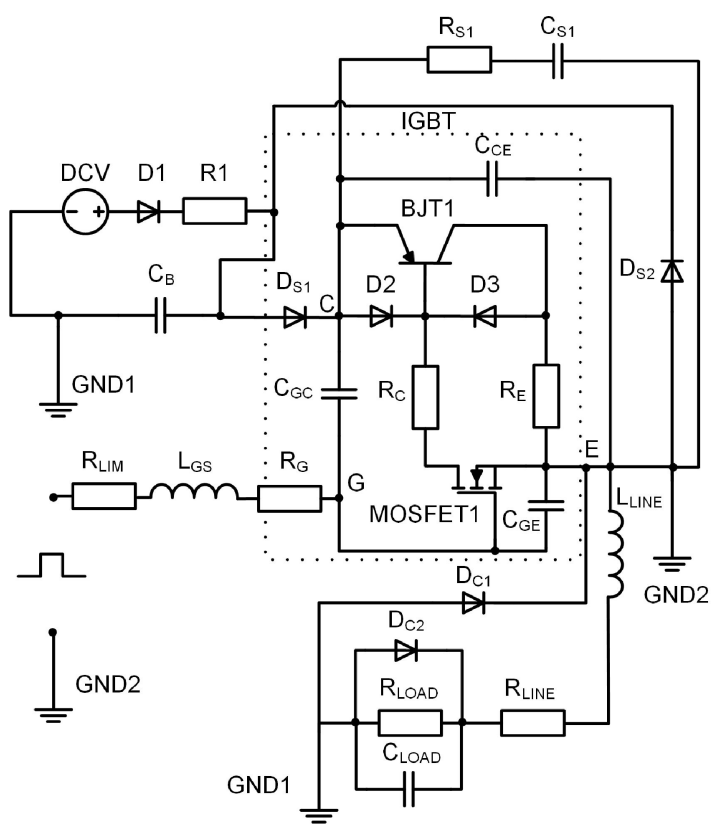

Fig. 6. Optimized circuit of the electroporator based on IGBT switch.

The $R_{S 1}=1$, while the optimal value for the $C_{S 1}$ has been found using simulation results, which are presented in Fig. 7.

As it is apparent from Fig. 7 the reverse biased voltage during transient processes due to the parasitic parameters of the electroporator circuit has been completely compensated even when the high inductance value of $10 \mathrm{H}$ is used. Both the switching dynamics of the IGBT and the shape of the output pulse have no oscillations or voltage spikes. However, there is still a risk of a spark occurring in the cuvette during electroporation, which implies that the value of $\mathrm{C}_{\mathrm{S} 1}$ equal to $5 \mathrm{nF}-10 \mathrm{nF}$ is preferable, ensuring a considerable reserve of $\mathrm{dI} / \mathrm{dt}$ and $\mathrm{dV} / \mathrm{dt}$ limitation. 


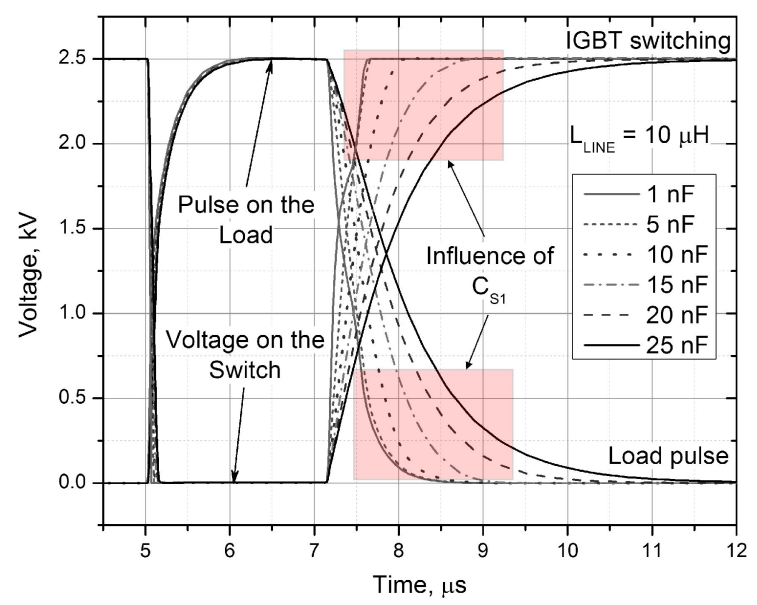

Fig. 7. Switching dynamics and the output pulse shape dependence on snubber capacitance.

Based on the proposed PSPICE model the pulse forming unit of the electroporator has been developed, however certain trade-offs on the rise and fall times have been made, which negatively affected the minimum generated square wave pulse duration $(5 \mathrm{~s})$. The prototype of the electroporator has been made. In order to estimate the adequacy of the model to simulate the experimental output pulse parameters the simulation data has been compared to the measurement results in the $5 \mathrm{~s}-30$ s pulse range, when the duration of the rise and fall time is considerable compared to the total pulse width.

\section{EXPERIMENTAL RESULTS}

The typical output pulses of the developed electroporator with parasitic load compensation and dampening circuit have been compared to the simulation data of the model and are shown in Fig. 8.

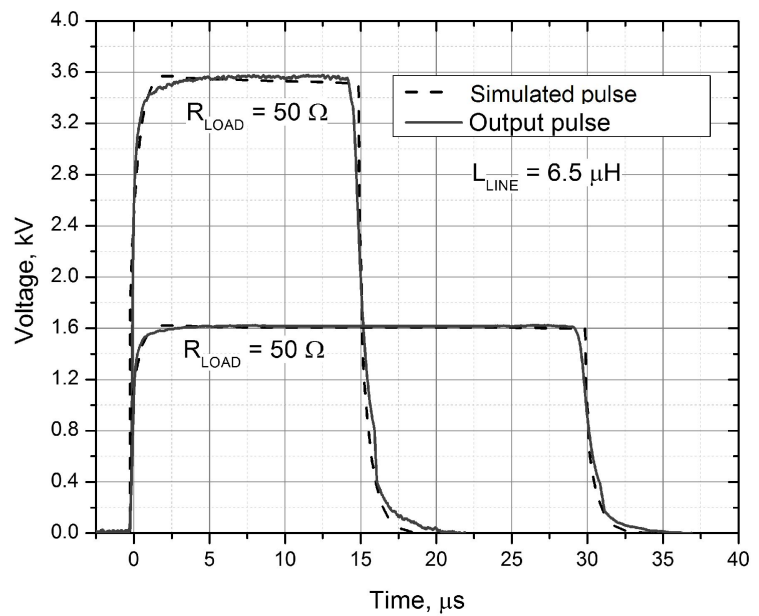

Fig. 8. The experimental and the simulated output pulses of the microsecond electroporator (15 s and $30 \mathrm{~s}$ pulses are shown).

The pulse has been divided into three regions: turn on transient $(10 \%-90 \%$ pulse amplitude), turn off transient (90\%-10\% pulse amplitude) and the pulse plateau (90\%$100 \%$ pulse amplitude). The simulation uncertainties for the turn on and the turn off transients were evaluated on the time scale, while in the plateau case the difference in amplitude was investigated. Taking into account the $1.5 \%$ DC accuracy variations of the oscilloscope and the $1 \%$ resistance value uncertainty, the simulation model uncertainty in the plateau region was $< \pm 3 \%$. On the time scale due to the high accuracy of the oscilloscope $( \pm 0.4 \mathrm{~ns})$, the influence of the measurement equipment has been neglected. The time scale uncertainties of $< \pm 1.2 \%$ for the turn on transient and the $< \pm 5 \%$ for the turn off transient across the whole diapason of the generated pulses have been ensured. It has been confirmed that the simulation results are in acceptable compliance with the experimental data.

\section{CONCLUSIONS}

A flexible PSPICE model for compensation of the transient processes in the electroporator circuit has been proposed. Based on the simulation results a parasitic load handling and dampening support has been implemented in the electroporator circuit. The simulation results are in acceptable compliance with the experimental data. The developed electroporator protototype generates $5 \mathrm{~s}-10 \mathrm{~ms}$ square wave electrical pulses up to $4 \mathrm{kV}$.

\section{REFERENCES}

[1] J. Gehl, "Electroporation: theory and methods, perspectives for drug delivery, gene therapy and research", Acta Physiologica Scandinavica, vol. 177, no. 4, pp. 437-447, 2003. [Online]. Available: http://dx.doi.org/10.1046/j.1365-201X.2003.01093.x

[2] M. P. Rols, "Electropermeabilization, a physical method for the delivery of therapeutic molecules into cells", Biochimica et Biophysica Acta (BBA) - Biomembranes, vol. 1758, no. 3, pp. 423 428, 2006. [Online]. Available: http://dx.doi.org/10.1016/j.bbamem. 2006.01.005

[3] Y. Chenguo, G. Fei, L. Chengxiang, S. Caixin, "Gene transfer and drug delivery with electric pulse generators", Current Drug Metabolism, vol. 14, no. 3, pp. 319-323, 2013. [Online]. Available: http://dx.doi.org/10.2174/1389200211314030007

[4] W. Korohoda, M. Grys, Z. Madeja, "Reversible and irreversible electroporation of cell suspensions flowing through a localized DC electric field", Cellular \& molecular biology letters, vol. 18, no. 1, pp. 102-119, 2013. [Online]. Available: http://dx.doi.org/10.2478/ s1 1658-012-0042-3

[5] V. Novickij, A. Grainys, J. Svediene, S. Markovskaja, A. Paskevicius, J. Novickij, "Irreversible electropermeabilization of the human pathogen Candida albicans: an in vitro experimental study", European Biophysics Journal, pp. 1-8, 2014.

[6] A. Lucinskis, V. Novickij, A. Grainys, J. Novickij, S. Tolvaisiene, "Modelling the cell transmembrane potential dependence on the structure of the pulsed magnetic field coils", Elektronika Ir Elektrotechnika, vol. 20, no. 8, pp. 9-12, 2014. [Online]. Available: http://dx.doi.org/10.5755/j01.eee.20.8.8432

[7] M. Puc, S. Corovic, K. Flisar, M. Petkovsek, J. Nastran, D. Miklavcic, "Techniques of signal generation required for electropermeabilization: Survey of electropermeabilization devices", Bioelectrochemistry, vol. 64, no. 2, pp. 113-124, 2004. [Online]. Available: http://dx.doi.org/10.1016/j.bioelechem.2004.04.001

[8] W. Zhaohui, Z. Junming, W. Xinke, S. Kuang, "Analysis of stray inductance's influence on SiC MOSFET switching performance", IEEE Energy Conversion Congress and Exposition (ECCE 2014), pp. 2838-2843, 2014.

[9] D. Bortis, J. Bielaand, J. W. Kolar, "Transient behavior of solid state modulators with Matrix Transformers", 17 IEEE Int. Pulsed Power Conf. (PPC), pp. 1396-1401, 2009.

[10] N. Mohan, T. M. Undelandand, W. P. Robbins, Power Electronics John Wiley \& Sons: United States of America, pp. 631-634, 2003.

[11] A. Lemmon, M. Mazzola, J. Gafford, C. Parker, "Stability considerations for silicon carbide field-effect transistors", IEEE Trans. Power Electronics, vol. 28, no. 10, pp. 4453-4459, 2013 [Online]. Available: http://dx.doi.org/10.1109/TPEL.2012.2226473

[12] J. F. Donlon, E. R. Motto, E. Wiesner, E. Stumpf, S. Iura, H. Uemura "Effect of pulse width on dynamic characteristics of high voltage IGBTs", IEEE Energy Conversion Congress and Exposition (ECCE 2014), 2014, pp. 2887-2892. 